\title{
Loss of Immunohistochemical Expression of Succinate Dehydrogenase (SDH) B
}

National Cancer Institute

\section{Source}

National Cancer Institute. Loss of Immunohistochemical Expression of Succinate

Dehydrogenase (SDH) B. NCI Thesaurus. Code C156463.

An immunohistochemical test result indicating the loss of expression of succinate dehydrogenase (SDH) B in the neoplastic cells of a tumor sample. 